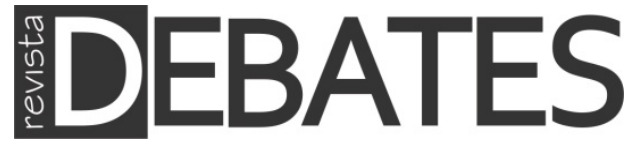

\title{
Os objetivos dos partidos no Brasil (1982-2018): construindo o IOP
}

\author{
Party objectives in Brazil (1982-2018): building the IOP
}

\author{
Maurício Michel Rebello \\ Gustavo Giora \\ Matheus Henrique Gomes Pereira
}

\section{Resumo}

Há várias interpretações teóricas sobre os objetivos dos partidos políticos ao longo dos dois últimos séculos, as quais culminam com denominaçôes de tipos partidários, como partido de massas, partido catch-all e partido cartel, por exemplo. Neste artigo, adotamos a perspectiva de Wolinetz, para a qual os principais objetivos de partidos políticos seriam: vote-seeking, policy-seeking e office-seeking. A partir de um modelo de escolha racional, propomos a criação do Índice de Objetivos Partidários (IOP). Para a utilização do índice, coletamos dados do Tribunal Superior Eleitoral (TSE) para as eleiçóes de governos estaduais de 1982 a 2018. Os resultados indicam um bom aproveitamento do índice, podendo-se situar os objetivos dos principais partidos políticos brasileiros em um continnum.

\section{Palavras-chave}

Partidos Políticos; IOP; Sistema Partidário Brasileiro; Governos Estaduais; Escolha Racional.

\section{Abstract}

There have been many theoretical interpretations about political parties' objectives throughout the last two centuries, which culminate in the denomination of party types, like mass party, catch-all party and cartel party, for example. In this paper, we adopt Wolinetz's perspective, for whom the main objectives of the parties are: vote-seeking, policy-seeking e office-seeking. Based on a rational choice model, we propose the creation of a Party Objectives Index (IOP). To use the index, we collected data from the Tribunal Superior Eleitoral (TSE) for government state elections from 1982 to 2018. These results indicate a good performance of the index, which can situate the main objectives of the Brazilian political parties in a continuum.

\section{Keywords}

Political Parties; IOP; Brazilian Party System; State Governments; Rational Choice. 


\section{Introdução ${ }^{1}$}

Os estudos sobre as organizaçóes partidárias têm sua tradição no campo da Ciência Política (DOWNS, 1999; DUVERGER, 1970, KATZ e MAIR, 1997; KIRCHHEIMER, 1966; MICHELS, 1979; PANEBIANCO, 2005; SARTORI, 1982). Diante de uma vasta bibliografia, observa-se a necessidade de realizar um estudo acerca das funçóes e dos objetivos dos partidos políticos nas democracias contemporâneas (MANIN, 1995; MAIR, 2003; WOLINETZ, 2002).

Nessa sequência, compreendemos a existência de objetivos partidários dentro de uma perspectiva de escolha racional, na qual possamos situar as organizaçóes partidárias em um continnum. Assim sendo, propomos, a partir de dados eleitorais agregados, a criação de um índice denominado Índice de Objetivos Partidários (IOP). Ao longo deste trabalho, demonstramos que o indicador proposto serve de referência no posicionamento dos partidos políticos sobre os três principais objetivos partidários, de acordo com W olinetz (2002), sendo estes: a busca por votos (vote-seeking), a busca por políticas públicas (policy-seeking) e a busca por cargos (office-seeking).

Aplicamos o IOP a partir de dados sobre a conquista de cargos para governadores das unidades federativas do Brasil, abrangendo como objeto de análise um período que vai de 1982 a 2018, totalizando 261 eleições para governos estaduais. Para a aplicaçáo deste indicador, optamos por considerar apenas os partidos que obtiveram ao menos $5 \%$ dos governos estaduais nos últimos 35 anos. Assim, a escolha dos partidos se deu pelo seu grau de relevância em termos eleitorais e, portanto, foram incluídos sete partidos (MDB, PSDB, PT, DEM, PSB, PP e PDT).

O IOP é de fácil aplicação matemática e pode ser utilizado em outros sistemas eleitorais, para além do sistema brasileiro. Entretanto, a condição de uso é de que seja uma eleição majoritária e que permita coligaçóes eleitorais. Os resultados indicam uma ótima satisfação do índice (com matriz de correlaçôes extremamente associadas). Além disso, o resultado do índice implica em discussōes teóricas sobre quais são os principais objetivos das organizaçôes partidárias e qual modelo teórico é compreendido: partido de massas, catch-all e cartel.

Ademais, cabe destacar que os três objetivos são independentes entre si em nosso modelo. Assim, não necessariamente uma organização que objetive cargos não objetiva, também, políticas públicas, por exemplo. Portanto, os resultados indicam que

\footnotetext{
${ }^{1}$ Agradecemos imensamente à contribuição dos pareceristas. Se erros persistem, são de nossa exclusiva responsabilidade.
} 
um novo indicador da Ciência Política pode estar surgindo - é necessário um conjunto de estudos maiores para mostrar a utilidade e o valor teórico e metodológico do índice.

\section{Um modelo de escolha racional}

Dentro das linhas institucionalistas das ciências sociais, cada vez mais determinados processos políticos e sociais são descritos como influenciados pela noção de path-dependence. Esse conceito vem geralmente agregado e dando suporte a alguns aspectos cuja sistematização, em linhas gerais, se deve a Pierson (2000). O mesmo autor aponta que tais definiçóes contrastam com conhecidas formas de explicação e argumentação vistas na Ciência Política, na qual, em regra, se atribuem grandes resultados a grandes causas e se valoriza a prevalência de resultados previsíveis e iguais para situaçóes inicialmente similares ou idênticas.

Por essas razóes, a teoria piersoniana incorpora a necessidade de retornos crescentes ao path-dependence para uma análise mais apropriada. De seu lado, os mesmos retornos crescentes geram, ou podem gerar, processos de self-reinforcing ou feedback positivos. É exatamente a incorporação de retornos crescentes que garante racionalidade (mesmo que parcial) a uma análise path-dependent, ao mesmo tempo em que diminui sua aleatoriedade.

Com retornos crescentes, os atores passam a ter fortes incentivos na busca de uma opção que garanta alguma vantagem inicial capaz de gerar feedbacks positivos. Uma vez garantidos os retornos, a simbiose entre retornos crescentes e o feedback positivo pode levar a uma escolha repetida por determinado caminho, de modo que a opção anterior interfere diretamente na opção seguinte, e assim sucessivamente.

Retornos crescentes são um fator verificável em processos de escolha de formas organizacionais alternativas. $\mathrm{O}$ modelo arthuriano permite estudar o processo de difusão dessas escolhas. Seu principal resultado é que, se a probabilidade de escolher uma ação aumenta com sua adoção, as primeiras adoçóes do processo podem levar a selecionar uma delas e excluir as outras. Nesse contexto, procedimentos subótimos podem dominar a estrutura de longo prazo, já que eventos históricos acontecidos no começo do processo podem determinar equilíbrios arbitrários, mas estáveis.

Arthur (1994) aponta, em termos econômicos, que quatro são as características necessárias para que se produzam retornos crescentes: (a) estrutura fixa de custos, (b) processo de aprendizagem, (c) processo de coordenação e (d) expectativas adaptativas.

A estrutura fixa de custos, neste caso, é entendida como aquela capaz de conferir melhores resultados (payoffs) quanto mais adesão obtiver. Sendo os custos de manutençáo desse sistema fixos, podem ser divididos entre todos seus aderentes, 
diminuindo o custo unitário. Quando existem poucas estruturas e com custos fixos muito elevados, indivíduos e organizaçóes têm forte incentivo para identificar e buscar aderir a apenas uma delas, reduzindo o custo unitário.

Os processos de aprendizagem têm como base a ideia de que o uso contínuo de um sistema gera retornos maiores que o seu uso esporádico ou temporário. A repetição leva a que os agentes aprendam a usar de forma mais eficiente o sistema que lhes é proposto. Já os efeitos de coordenação estão presentes quando o retorno recebido por um agente, individualmente, por determinada opção, é capaz de aumentar quando outros indivíduos também fazem uma opção.

Segundo a perspectiva das expectativas adaptativas, os agentes atualizam suas expectativas sobre o futuro dependendo da concretização ou não de suas expectativas no período anterior. A aplicação desse conceito-modelo leva em consideração o fato da periodicidade das eleiçóes em um regime democrático, que conduz os agentes a atualizarem suas expectativas de futuro com base em seus erros anteriores de previsão sobre o desempenho atual dos agentes políticos.

Ainda assim, um mecanismo mais sofisticado também atua na formação das expectativas dos eleitores: a hipótese de expectativas racionais. Esta implica que os agentes incorporem rapidamente as informações disponíveis na formação das expectativas, que náo cometam e nem repitam erros simples, se dispóem de informaçóes que os podem prevenir, e que as expectativas devem ser consistentes com o modelo que os agentes acreditam ser governante.

Pierson (2000) indica que, num contexto de path-dependency e retornos crescentes, a análise política deve ser caracterizada por outras quatro características adicionais ao modelo de Arthur (1994): (a) equilíbrio múltiplo, contingenciamento, (c) tempo e sequência dos fatos e (d) inércia.

Hayek (1960) afirma que as lições de aprendizagem social são um processo de experiências cumulativas de geraçóes passadas. Esse processo consiste nas experiências que sobreviveram a um teste temporal e que acabam por se incorporar na nossa linguagem, tecnologia e instituiçôes. $\mathrm{O}$ autor considera isso como a transmissão do nosso estoque de conhecimento no tempo. Esse é o filtro primeiro da aprendizagem presente nesse processo incremental que é capaz de apontar os resultados (payoffs), embora náo exista a garantia de uma solução do problema, apenas o poder de afetação dos eventos passados sobre os que estão por ocorrer.

As teorias da escolha racional procuram dar conta da análise dos sistemas políticos a partir do conceito de racionalidade. Downs (1999) tinha como objetivo 
74 | Maurício Michel Rebello, Gustavo Giora e Matheus Henrique Gomes Pereira

evidenciar, através de um modelo de análise, que há uma regra comportamental concernente ao governo democrático. Seu ponto de partida estava no conceito de racionalidade, análogo à racionalidade da teoria econômica clássica, pressupondo que os agentes no campo da política têm comportamentos idênticos aos do campo da economia, ou seja, os indivíduos buscam maximizar seus interesses pessoais, os benefícios. Se na teoria econômica isso implica em que as empresas maximizam os lucros, assim como os consumidores maximizam a utilidade, no campo da política significa dizer que os partidos políticos têm por objetivo maximizar os votos, e os eleitores buscam maximizar seus benefícios analisando racionalmente seus ganhos em relação aos partidos que disputam o poder.

O modelo de análise proposto por Downs (1999) considera a necessidade de estabilidade como fundamental para a sua aplicação, pois a avaliação tanto por parte dos partidos quanto dos eleitores somente pode ocorrer de maneira eficiente em um cenário no qual se mantenha um ordenamento, um grau de previsibilidade mínimo. De outro modo, a variação constante das regras obscureceria a capacidade analítica dos indivíduos. Nesse sentido, o governo deve ser responsável pela estabilidade política, assegurando que as bases da democracia sejam garantidas, como, por exemplo, as eleiçóes periódicas, a garantia dos direitos individuais e a liberdade de expressão, em suma, os pressupostos da democracia liberal.

O postulado da racionalidade afirma que os agentes devem maximizar seus payoffs em um determinado quadro de possibilidades, de outra forma o comportamento seria considerado não-racional. Tsebelis (1998), em sua teoria dos jogos ocultos, introduz o conceito de "jogos em múltiplas arenas" a partir do qual procura dar conta da problemática referente às escolhas dos agentes e da análise realizada pelo pesquisador, sem abandonar o princípio da racionalidade. Quando as escolhas dos agentes representam uma escolha subótima, em que os ganhos não foram os melhores possíveis, dir-se-ia que há um componente de irracionalidade ou de uma estratégia não eficiente.

Segundo Tsebelis (1998), as escolhas subótimas em verdade seriam apenas aparentes, o que há de fato é uma discordância entre as açóes do agente e a análise do observador. As possibilidades de explicação emergem da suposição de que o agente de fato não maximizou seus payoffs ou então o observador não considerou a totalidade do jogo, ou seja, o conjunto dos jogos que estariam sendo jogados. No caso específico do agente, a explicação de uma escolha subótima decorre da impossibilidade de se escolher racionalmente, mas isso não seria relevante para a análise dos fenômenos políticos. Em 
segundo lugar, o agente teria cometido um erro, porém esse fato não pode se repetir com frequência, pois será esperado que o agente corrija seu comportamento.

A abordagem da teoria dos jogos ocultos afirma que, se a escolha dos agentes não representa uma estratégia ótima mesmo que haja um conjunto adequado de informaçóes em posse do agente, é necessário o tratamento do fenômeno a partir da inserção deste nas múltiplas arenas, em outras palavras, não se deve admitir um componente não-racional sem o enfrentamento do fenômeno inserido em uma rede ou teia de jogos.

Nesse sentido, o que queremos demonstrar é que os partidos são capazes de fazer uma leitura bastante razoável de suas capacidades e de seus resultados esperados utilizando estratégias subótimas, mas maximizadoras em termos de expectativas adaptativas.

\section{A racionalidade dos partidos existe?}

Nosso quadro teórico parte do pressuposto de Downs (1999), segundo o qual, nas democracias, as organizaçóes partidárias buscam votos, independentemente dos outros inúmeros objetivos que as organizaçóes possam ter. Em qualquer lugar do mundo democrático, partidos políticos entram no campo da disputa política tendo como objetivo máximo os votos do eleitorado. Quanto maior o número de votos obtidos pelos partidos políticos, seus objetivos essenciais foram atingidos.

Evidente que a abordagem por nós empregada deve ser criticada pelo seu viés determinista de diminuir os objetivos da organização partidária em uma única dimensão (votos). No entanto, é a existência desta crítica que dá sentido ao nosso modelo teórico. Inúmeros autores, ao longo dos últimos séculos, tentaram analisar este estranho "animal" que são os partidos políticos nas democracias contemporâneas (DOWNS, 1999; DUVERGER, 1970; KATZ e MAIR, 1997; KIRCHHEIMER, 1966; MICHELS, 1979; PANEBIANCO, 2005; SARTORI, 1982). Em alguma medida, todos esses autores identificaram objetivos que tais partidos políticos buscavam alcançar, como recursos financeiros, militantes, filiados, ideologias, poder, prestígio etc.

Há muito a debater sobre tais objetivos, mas não há espaço para tanto neste trabalho². Sendo assim, propomos reduzir nossa discussão teórica em apenas três dimensóes: votos, cargos e políticas públicas, que seriam as três dimensōes mais relevantes nas organizaçôes partidárias ao longo do tempo (WOLINETZ, 2002). Em

\footnotetext{
${ }^{2}$ Para uma grande revisão bibliográfica sobre as diferentes compreensôes dos partidos políticos, consultar Mayer (2017).
} 
76 | Maurício Michel Rebello, Gustavo Giora e Matheus Henrique Gomes Pereira

verdade, a proposiçáo deste autor resguarda similaridades com as principais características de cada modelo partidário debatido pela bibliografia de partidos políticos: partidos de massa de Duverger (policy-seeking), catch-all parties de Kirchheimer (vote-seeking) e, finalmente, o partido cartel de Katz e Mair (officeseeking).

É recorrente, na bibliografia da Ciência Política, um eterno mal-estar pelo que os nossos partidos políticos produzem de resultado para as democracias contemporâneas. Não obstante a orientação epistemológica nessa discussão, o fato é que desde o início das democracias representativas, os partidos políticos são onipresentes (LAPALOMBARA, 2007). Deste modo, pode-se criticar a existência partidária, mas não se pode negá-la, nem mesmo a desconsiderar como elemento crucial nas atuais democracias. Apesar da forma resumida, apresentaremos, a seguir, os três principais modelos partidários para se compreender o modelo representativo atual.

Logo após a Segunda Guerra Mundial, Maurice Duverger escreveu Os Partidos Políticos (1970 [1951]). Neste livro, Duverger conceitua o que viria a ser chamado de partidos de massa. Essa "espécie" partidária teria ocorrido, principalmente, entre o início do século XX até meados do mesmo século. Suas características são: riqueza de militância, financiamento organizacional pelos próprios filiados, constituição de um nicho eleitoral determinado (classe gardée) e uma clara ideologia com conteúdo programático demarcado. Nesse período, Lipset e Rokkan (1967) mostram como o sistema partidário europeu era baseado em clivagens sociais, mostrando uma forte vinculação entre a sociedade civil e as organizações partidárias, com claras tendências de "congelamento" das opçóes partidárias, mostradas a partir de baixos indicadores de volatilidade eleitoral (BARTOLINI e MAIR, 1990).

A questão chave para compreender os partidos de massa está em seu valor de tipo puro weberiano e não um modelo a ser seguido, ou seja, há uma idealização sobre as características dos partidos de massa, inclusive com claras tendências de crença de que é esse o sistema partidário mais adequado para as democracias contemporâneas (REBELLO, 2013). Em que pese a importância de Duverger (1970) para a compreensão da organização partidária, sua visão é muito vinculada à Europa. A bibliografia norte-americana sobre partidos políticos, por exemplo, interpretou os sistemas partidários - incluindo o norte-americano - de forma diversa (MAYER, 2017).

O "tipo" partidário de massa não objetiva somente ganhar eleições (voteseeking). Ele nem sequer pode almejar isso, dado que sua busca por votos se dá somente entre determinada clivagem social. Tampouco objetiva alcançar cargos a qualquer custo 
(office-seeking), dado que, para isso, precisaria realizar alianças heterogêneas para estar no maior número de governos possíveis. Seu objetivo primordial e raison d'être está em fornecer uma representaçáo política voltada a um conjunto de eleitores bem definidos, com forte conteúdo programático (policy-seeking). Um comentário importante é que nem todos os partidos políticos do início do século XX eram assim. Esse tipo puro serviria mais a partidos socialistas ou social-democratas (DUVERGER, 1970). É nesse sentido que Wolinetz (2002) compreende que um dos objetivos essenciais para algumas organizaçôes partidárias é a busca por conteúdo programático, já que essa seria a principal demanda (input) de uma parte dos mandantes.

No Pós-Guerra, Kirchheimer (1966), em um ensaio, percebeu que as legendas já não mais correspondiam às características descritas anteriormente. Os partidos teriam ampliado seu leque eleitoral, por isso o nome "exagerado" de partido pega-tudo. Mas o fato é que eles aumentaram "a expectativa de mais eleitores" (KIRCHHEIMER, 1966, p. 186). Com isso, houve perda de identificação partidária, queda de militantes, mudança no perfil de financiamento e, principalmente, um conteúdo programático mais difuso (PANEBIANCO, 2005). Neste contexto, principalmente pós-década de 1980, a volatilidade eleitoral dos sistemas partidários se torna mais alta, e há claras mudanças de sentido da representação, como a chamada democracia de público (MANIN, 1995).

Como o próprio nome designa, o objetivo do catch-all é conseguir o maior número de votos possíveis (vote-seeking). Ele se torna uma máquina eficiente de conseguir apoio do público. Aqui cresce a proeminência de marketing em detrimento de militantes, a TV ganha destaque e, assim, os partidos náo se restringem a conseguir apoio em um único nicho, mas em uma gama de diversos grupos. Aquilo que Sartori (1982) denomina como um entrecruzamento de clivagens.

Por fim, surge a denominação partido cartel, cuja aproximação com o Estado é tanta que o partido pode ser confundido com o próprio Estado (KATZ e MAIR, 1997). Aqui o objetivo é explícito: obter recursos do Estado. Ainda mais distante da sociedade civil e com pouquíssimo conteúdo programático, a noção de partido cartel transforma as organizaçóes partidárias em uma função meramente procedimental, numa distante interpretação de como o partido político era pensado na primeira metade do século XX (MAIR, 2003).

Nesta última dimensão, o objetivo é o mais claro de todos: garantir a conquista de estar presente no Estado (VAN BIEZEN e KOPECKÝ, 2007). Contudo, para isso, pertencer aos governos, ter acesso aos gabinetes ministeriais, secretarias e órgáos se torna 
fundamental. Destarte, a busca por cargos, por patronagem, de maneira geral, é o principal objetivo da organização partidária (office-seeking).

Obviamente, ao tentar resumir a riqueza das organizaçóes partidárias por meio de três tipos puros, tais construções teóricas recebem inúmeras críticas da literatura especializada. A principal delas é que as organizaçóes partidárias não podem ser enquadradas em um modelo parcimonioso em que apenas três tipologias são aceitas. Em verdade, existem muitas outras características e deveríamos alargar mais as bases da taxologia de "espécies" partidárias (GUNTHER e DIAMOND, 2003). Em estudo recente, mostrou-se como existe uma rica variedade de partidos políticos na América Latina, não podendo estes ser compreendidos única e exclusivamente pela bibliografia europeia ou norte-americana (MAYER, 2017). Em outro sentido, Wolinetz (2002) chama a atenção para o fato de que, embora devêssemos reconhecer que alguns tipos partidários estão mais presentes em determinados momentos históricos, isso não significa que eles não possam interagir ao mesmo tempo. Desta forma, o autor defende a tese de que podemos considerar os partidos políticos como um triângulo de objetivos: vote, office ou policy-seeking simultaneamente.

É nesse mesmo sentido que defendemos a existência de uma racionalidade das organizaçôes partidárias. Partidos políticos não são a mera soma dos filiados que os compóem, eles são fruto de vários fatores ao longo da história. Por isso, talvez não faça sentido tentar encontrar um único tipo puro das organizaçóes partidárias em um determinado país, como a afirmação de que o Brasil seria o reino do catch-all parties (MAINWARING, 2001).

Provavelmente, na maioria das democracias atuais, todos os partidos políticos almejem votos, cargos e políticas públicas. Entretanto, isso não significa dizer que não há diversas escalas entre tais objetivos. Alguns partidos de extremo conservadorismo na Europa, como a Alternativa para a Alemanha (AfD), por exemplo, almejam políticas públicas como seu objetivo primordial (como regras mais duras para os estrangeiros residirem e trabalharem em seu país). Ao tomar posições mais extremas, tais partidos políticos ficam mais restritos a alguns nichos eleitorais, dado que seu objetivo não é o de "suavizar" o discurso para conseguir mais votos ou, de forma diversa, realizar alianças com o partido governante para obter cargos. Nestes mesmos países, partidos maiores e mais tradicionais possuem um conteúdo programático mais flexível. Além disso, algumas coalizóes, antes impensáveis - como aliança entre o SPD e CDU na Alemanha -, tornam-se possíveis dado o potencial de cargos que estar em um governo pode trazer. Assim sendo, nosso pressuposto teórico é de que podemos produzir uma escala de preferências das organizaçôes partidárias na qual podemos dispô-las em um continnum 
em três dimensôes (votos, cargos ou políticas públicas), como a figura geométrica a seguir demonstra.

Figura 1 - Representação ilustrada do Índice de Objetivo Partidário (IOP)

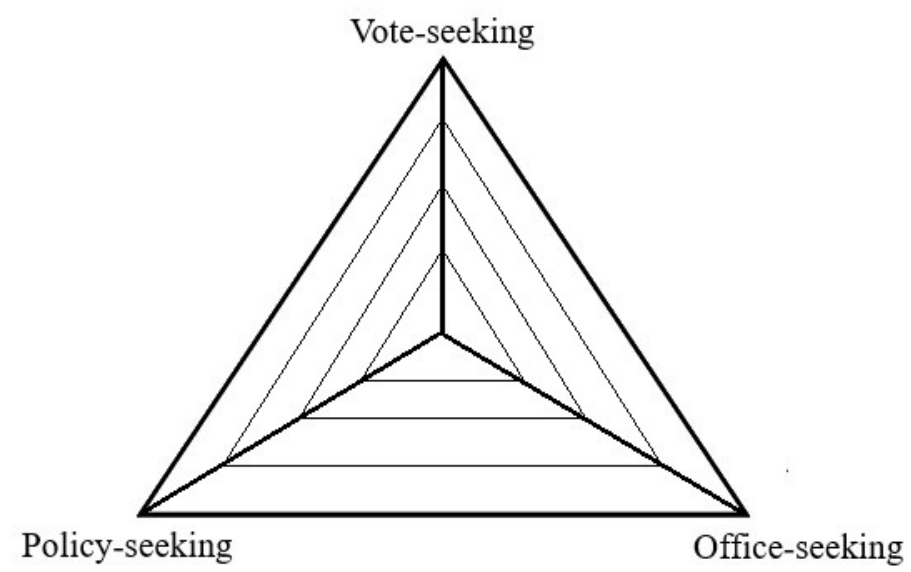

Fonte: Adaptado de Wolinetz (2002).

\section{Construindo axiomas: as diferentes racionalidades partidárias}

Como falado anteriormente, a afirmaçáo de que os partidos políticos objetivam, primordialmente, votos, é algo que compartilhamos com Downs (1999). Essa visão pressupóe que todos os partidos políticos queiram ganhar o máximo de votos possíveis dos eleitores - no limite, a totalidade dos mandantes. Felizmente, para um sistema democrático plural, eles não conseguem. Em algum momento, seja por diversas variáveis - cuja principal é a impossibilidade prática -, os partidos políticos deixam de perseguir única e exclusivamente o objetivo de conquistar votos, realizando, assim outros objetivos.

Axiomal. Organizaçóes partidárias buscam votos como seu primeiro objetivo. Todavia, quando da impossibilidade de alcançar todos os eleitores, as organizaçóes partidárias deixam de perseguir seu primeiro objetivo. 
Restando outros objetivos, quais sáo eles segundo boa parte da literatura? Acreditamos que a maioria das organizaçóes possua interesse em aplicar determinadas políticas públicas como grande objetivo. Todos os seus integrantes possuem uma ideologia em várias questôes: participação do Estado na economia, valores morais, valores religiosos, valores democráticos e autoritários, valores sobre a preservação do meio ambiente etc. Em geral, a distinção clássica é a diferença em termos de pensamento sobre a economia; ainda assim, existem inúmeras escalas de pensamento no qual o ser humano é classificado e colocado em um continnum. Os integrantes dos partidos também assim o são, fazendo com que a organização partidária retenha certa ideologia.

Axioma2. Organizaçóes partidárias, quando não alcançam o objetivo de ganhar votos, buscam as políticas públicas como principal objetivo.

E quando partidos políticos não possuem objetivos primordiais de ganhar votos ou aplicar políticas públicas? Existe outro objetivo bastante atrativo: ganhar espaço dentro do Estado. Desde o surgimento da máquina partidária moderna, muitos autores perceberam o quanto a estrutura partidária almeja o Estado (MICHELS, 1979; KATZ e MAIR, 1997; MAIR, 2003; VAN BIEZEN e KOPECKÝ, 2007). Assim, não seria nada novo supor que a busca - aqui descrita genericamente como cargos - é o objetivo em si de algumas organizações partidárias. A busca por cargos ou patronagem não é, necessariamente, igual a busca por rent-seeking (ADSERÁ, BOIX e PANE, 2003). Tal termo tem conotação pejorativa na arena partidária, já que significa obter rendas para si. Todavia, é visível que a maioria dos partidos políticos possuem um comportamento rent-seeking (VAN BIEZEN e KOPECKÝ, 2007).

Axioma 3. Quando o objetivo primeiro das organizaçóes partidárias não é o de ganhar votos ou aplicar políticas públicas, ele é, necessariamente, o de buscar a conquista de cargos.

A partir do que afirmamos até aqui, significa então que cada partido político possui um objetivo diferente? A resposta é sim e não. Sim, porque as organizaçôes são diferentes ao longo do tempo e do espaço. Não, porque nenhuma organização é um modelo de tipo puro, e sim um mix de objetivos dentro de uma mesma organizaçáo. Assim, todas as organizaçóes possuem esses três objetivos acima descritos, ainda que o grau de preferência por eles varie em cada organização. 
Axioma 4. Todas as organizaçôes partidárias possuem objetivos. Estes objetivos são: votos, políticas públicas ou cargos. Existe um continnum de preferências em cada organização política que se entrecruzam e são independentes entre si, formando, desta forma, um mix triangular dos três objetivos.

A partir do modelo teórico exposto, pretendemos criar indicadores de fácil reprodução e compreensão para que os estudiosos das organizaçôes partidárias possam analisar quais sãos os objetivos das organizaçóes partidárias para que se possa compreender o modo de funcionamento dos partidos políticos nas democracias atuais.

\section{IOP - Índice de Objetivos Partidários}

A construção de indicadores utilizados na Ciência Política tem sido comum nas últimas décadas. Alguns deles, como o índice de fragmentação partidária (RAE, 1967), o índice do número efetivo de partidos políticos (LAAKSO e TAAGEPERA, 1979) e índice de volatilidade eleitoral (PEDERSEN, 1980), por exemplo, influenciaram a Ciência Política de tal maneira que esses indicadores são essenciais na interpretação das eleiçóes e do sistema partidário. Tais indicadores permitiram, por exemplo, um conjunto de estudos na política comparada nos quais os autores puderam comparar vários sistemas eleitorais e partidários em todo o globo (BARTOLINI e MAIR, 1990; LIJPHART, 2003; MAIWARING e TORCAL, 2005; NORRIS, 2008).

Evidente que nossa intenção é mais modesta. Ainda assim, dada a discussão teórica anterior, propomos a criação de um índice que englobe a busca, pelos partidos políticos, de três objetivos: 1) votos, 2) políticas públicas, 3) cargos. Todos os objetivos variam de 1 (maximização total do objetivo perseguido) a 0 (minimizaçáo total do objetivo perseguido) e devem ser analisados em separado. Esse indicador somente deve ser utilizado quando a competiçáo for majoritária e permitir coligaçóes. Os dados que precisamos são eleitorais (agregados) e devem conter as seguintes variáveis das organizaçóes partidárias que pretendem ser estudadas: total de candidaturas partidárias do respectivo cargo em disputa; total de candidaturas partidárias vitoriosas; tipo de candidatura partidária - se isolada, coligada como cabeça de chapa, coligada sem ser cabeça de chapa; consistência ideológica da coligação - consistente, semiconsistente e inconsistente. Em princípio, todas as eleiçôes que satisfizerem os critérios acima descritos podem utilizar o indicador. 


\section{Buscando votos (vote-seeking)}

Se partidos políticos desejam votos como seu primeiro objetivo, como podemos saber se a organização partidária, realmente, objetiva isto? A resposta são as candidaturas vitoriosas. Se as organizaçóes partidárias permitem uma grande busca por votos, não há sentido em disputar todas as eleiçôes e perder em todas. Um exemplo é considerar todas as eleiçóes para governador do estado de um partido que tem dezenas de candidaturas ao longo das décadas, mas ganhou muito poucas eleiçôes. Certamente, a organização partidária gostaria de alcançar este objetivo (ganhar eleiçôes, axioma um). Todavia, em função da realidade em que ela está inserida, sua tarefa é muito difícil. Por outro lado, partidos políticos que busquem maximizar sua vitória, em geral, tenderáo a permitir candidaturas somente com condiçóes de vitória, ou seja, em que o cálculo seja o de que é possível construir candidaturas com viabilidade eleitoral. Deste modo, propomos a utilização de um indicador, chamado de índice de eficiência absoluta (GIORA e GRABOSKI, 2015). Desta maneira:

$$
\text { Ief }(x)=\Sigma V(x) / \Sigma D(x) \text {; }
$$

Onde: $\sum \mathrm{D}(\mathrm{x})$ é o somatório de disputas do partido quando ele é cabeça de chapa $(\mathrm{x})$, e $\sum \mathrm{V}(\mathrm{x})$ é o somatório de vitórias do mesmo partido (x).

Suponha que um partido político (x) lançou 100 candidaturas a prefeito no estado de São Paulo e não tenha ganhado nenhuma prefeitura. O resultado será Ef $(\mathrm{x})=0 / 100=0$. Agora, suponha que ele ganhou em todas as disputas, $\mathrm{Ef}(\mathrm{x})=100 / 100$ $=1$. Nestes exemplos, temos os limites do indicador ( 0 a 1 ). Como mostraremos mais adiante, é crível supor que o primeiro caso seja de um partido político que busque outros objetivos que náo o voto. Já no caso do segundo, o cálculo racional de buscar votos foi perfeito.

\section{Buscando politicas públicas (policy-seeking)}

Aqui, devemos realizar uma ressalva: em princípio, todos os partidos políticos, ao buscarem o poder, possuem possibilidades de influenciar na tomada de decisão, e consequentemente, as políticas públicas. Contudo, são os partidos políticos mais ideológicos que possuem maior interesse em influenciar na aplicação de políticas públicas. Segundo a literatura especializada, nos últimos anos, houve uma queda de conteúdo ideológico nas organizações partidárias (KIRCHHEIMER, 1966; PANEBIANCO, 1982; KATZ e MAIR, 1997). Significa que tais partidos abdicaram de oferecer políticas públicas? De forma alguma. Todavia, seus objetivos principais não estariam em oferecer claros acenos ideológicos a um grupo determinado. Pelo contrário, caso esses partidos políticos fossem muito ideológicos, eles teriam dificuldade 
de conquistar outros setores sociais, renegando sua condição de catch-all parties. Mas como saber se a ideologia, ou o interesse por um conteúdo de políticas públicas está presente? A resposta é a inconsistência ideológica da coligação. Quando organizaçôes partidárias se coligam com extremos opostos, automaticamente, elas estáo limitando seu potencial de aplicação de políticas públicas. Um partido de esquerda cujo programa seja a estatização de parte dos meios de produção, ao se coligar com um partido extremamente liberal cujo programa é de desestatizaçáo da economia, sabe que sua agenda deve ficar muito mais limitada. Para a candidatura, isso tanto vale ao oferecer políticas públicas para os eleitores como para formar coalizões posteriormente. É por isso que, seja na Europa, seja na América Latina, é muito incomum ver organizaçôes partidárias de extremos opostos se coligarem entre si. No Brasil, por exemplo, partidos políticos mais à esquerda não realizam coalizóes ideológicas inconsistentes (KRAUSE e GODOI, 2010). Deste modo, para indicar se partidos políticos buscam políticas públicas (policy), criou-se o Índice de Consistência Ideológica (ICI):

$$
\operatorname{Ici}(x)=\Sigma C(x) / \Sigma D(x) \text {; }
$$

Onde: $\sum \mathrm{D}(\mathrm{x})$ é o somatório de disputas do partido (x), e $\sum \mathrm{C}(\mathrm{x})$ é o somatório de candidaturas consistentes e semiconsistentes do partido (x).

Aconselha-se o uso de uma classificação ideológica utilizada por pesquisadores especialistas na área. Suponha que aquele mesmo partido que lançou 100 candidaturas em São Paulo - aqui independe se é ou não cabeça de chapa, lance 100 candidaturas consistentes ou semi-consistentes. $\mathrm{O}$ resultado será $\mathrm{Ici}(\mathrm{x})=100 / 100=1$. Do lado contrário, o partido que não lança nenhuma candidatura consistente ou semiconsistente, tem que: $\operatorname{Ici}(\mathrm{x})=0 / 100=0$. É muito razoável supor que existam claras diferenças quanto à preocupação de conteúdo programático dessas candidaturas. Caso você realize este teste com organizaçôes partidárias extremas em um país, o resultado será próximo de um.

A opção de incluir coligaçôes semi-consistentes, ou seja, candidaturas de centro com a esquerda ou de centro com a direita, ocorre porque existem dúvidas de classificação quanto à distância ideológica entre partidos políticos (ZUCCO, 2011). O PSDB, por exemplo, é geralmente classificado ao centro - alguns estudos já o classificaram como centro-direita (MAYER, 2017). Assim, não seria razoável supor que uma aliança com o DEM - desde o tempo do antigo PFL, sempre classificado como pertencente ao bloco ideológico da direita -, por exemplo, inviabilize uma agenda programática próxima. Agora, a entrada de um partido como o PSOL certamente bloquearia as possibilidades de agenda desta aliança. Assim sendo, propomos um 
84 | Maurício Michel Rebello, Gustavo Giora e Matheus Henrique Gomes Pereira

indicador com certa flexibilidade, para, realmente, mostrar candidaturas que tenham alguma proximidade ideológica.

\section{Buscando cargos (Office-seeking)}

Nosso último indicador tenta captar se a organização partidária possui como objetivo os cargos. Propomos, para isso, ver em que ponto a organizaçáo partidária em questáo abdica ou não da cabeça de chapa. Quando uma organizaçáo concorre sem ser cabeça de chapa, ela abdica de seu potencial eleitoral. Evidentemente que a análise de uma única candidatura não nos permite afirmar isto. Mas, se ela sempre realiza tal comportamento, é provável que ela somente queira maximizar cargos (office-seeking). Deste modo, temos:

$$
\text { Icol }(x)=\sum c o(x) / \Sigma D(x)
$$

Onde: $\sum \mathrm{D}(\mathrm{x})$ é o somatório de disputas do partido $(\mathrm{x})$, e $\sum \mathrm{co}(\mathrm{x})$ é o somatório de candidaturas coligadas do partido (x) quando ele náo é cabeça de chapa.

Utilizando o mesmo exemplo anterior, se a candidatura do partido sempre for coligada, sem ser o cabeça de chapa, o resultado será Col $(x)=100 / 100=1$. Do lado contrário, caso suas candidaturas sejam sempre cabeça de chapa, o resultado será Col $(\mathrm{x})=0 / 100=0$. Em geral, partidos que não objetivem cargos - como primeiro objetivo - não se dispóem a participar de coligações sem ser cabeça de chapa.

Um comentário importante é que os indicadores são independentes entre si. Como mostraremos a seguir, eles diferem de modo substancial em seus objetivos. Teoricamente, não pode haver um partido que maximize todos os objetivos - tanto votos, como políticas públicas e, também, cargos - porque isto fere a ideia de lançar candidaturas próprias e, ao mesmo tempo, todas suas candidaturas serem coligadas sem ser cabeça de chapa. Em verdade, quase todas as organizaçóes partidárias no mundo compartilham destes três objetivos, porém, a intensidade com que variam os três indicadores permitirá que coloquemos as organizaçóes partidárias em um continnum tridimensional (WOLINETZ, 2002).

Outra ressalva é que nossa tentativa de criação de indicadores possui limites, já que trabalhamos com ideia de proxye não a análise do indicador em si. É por isso que propomos axiomas, já que é teoricamente impossível saber, realmente, os objetivos das organizaçóes partidárias. Mesmo em um survey com todos os filiados do partido, teríamos um conjunto de respostas heterogêneas e nem sempre verdadeiras - algum filiado afirmaria que o partido político como um todo somente busca cargos?

Importante destacar também que os partidos políticos não são unidades perfeitas. Reisman (2016), dialogando com a literatura internacional, destaca como 
partidos possuem "faces" distintas, como a parte que ocupa cargos no Executivo e Legislativo (party in public office), a direção nacional do partido (party on central office) e sua base (party on the ground). As disputas internas organizacionais levam a resultados que mostraremos a seguir, revelando uma maior proeminência de facçóes partidárias.

Assim, acreditamos que o IOP (Índice de Objetivos Partidários) é o instrumento de pesquisa mais adequado e acessível para se chegar a compreender os objetivos das organizaçôes partidárias. Este instrumento é simples, com cálculo simples e de fácil reprodutibilidade, possui uma boa cobertura da população, metodologicamente transparente e pode permitir séries históricas, algo desejável nas ciências sociais (PARANHOS et al., 2013).

\section{Procedimentos metodológicos e os limites do IOP}

Para aplicarmos o IOP, resolvemos, neste artigo, analisar as 261 eleiçóes para governos estaduais entre 1982 a 2018. Assim, trabalhamos com o total de eleiçóes e náo com uma amostra. Este banco de dados conta com dezessete variáveis e ocupou cerca de quarenta horas para ser construído³. Essas variáveis são as candidaturas partidárias vitoriosas e as candidaturas dos principais partidos políticos que envolvem, cada um, a criação de mais duas variáveis: (a) se houve coligação e, quando houve, qual sua consistência ideológica; (b) quando participou do pleito foi como cabeça de chapa ou como coligado. Além disso, o banco averigua se há continuidade do mesmo partido político no governo estadual e se houve reeleição.

Obviamente, existem limitaçóes em nossos índices. Em primeiro lugar, é importante salientar que o IOP atua como uma aproximação (proxy), sem, necessariamente, medir os reais conceitos discutidos na seção anterior. Em cada índice, há uma limitação. No caso do índice de eficiência absoluta, por exemplo, um partido pode lançar dez candidaturas e ganhar em sete e obter um índice de 0,7 , revelando altíssima busca por votos. Todavia, se um partido lançar cem candidaturas e ganhar em sete, obterá um índice de 0,07 , revelando uma baixíssima busca por votos. Veja que o número de eleiçôes vitoriosas é o mesmo e que se pode argumentar que a busca por votos foi idêntica - embora, como já explicamos, discordemos dessa interpretação.

No caso do índice de consistência ideológica, há um problema para o sistema partidário brasileiro: a classificação ideológica dos partidos. No caso brasileiro, para alguns especialistas, existe falta de coerência ideológica e uma dificuldade grande em

\footnotetext{
${ }^{3}$ Agradecemos os recursos recebidos pelo CNPq que viabilizaram esta pesquisa.
} 
situar os partidos em um continnum (ZUCCO, 2011). Além disso, pode-se deduzir que as coligaçóes são cálculos racionais pragmáticos e que isso não influencia no teor ideológico dos partidos políticos.

No caso do índice de procura por cargos, uma limitação é que, ao conquistar governos ou buscar votos (índice de eficiência absoluta), os partidos já estão buscando cargos. Nesse diapasão, governos com alta busca por votos também teriam alta busca por cargos.

Ainda que existam todos esses limites, optamos por tentar testar o IOP, pois, mesmo que ele tenha várias limitaçôes, o debate a que ele se propóe é extremamente útil à Ciência Política. Ademais, outros pesquisadores podem aperfeiçoá-lo no futuro.

\section{Os objetivos dos partidos politicos nos governos estaduais: aplicando o IOP}

A escolha dos partidos políticos se deu pelo grau de relevância em termos eleitorais. Assim, optou-se por considerar apenas aqueles que obtiveram pelo menos $5 \%$ dos governos estaduais nos últimos 35 anos. Desta maneira, foram incluídos sete partidos: MDB, PSDB, PT, DEM, PSB, PP e PDT. A Tabela 1 mostra o desempenho desses partidos no período estudado.

Tabela 1 - Número de governos estaduais conquistados no Brasil (1982-2018)

\begin{tabular}{l|l|l}
\hline \multicolumn{1}{c|}{ Partidos Políticos } & \multicolumn{1}{|c}{$\begin{array}{c}\text { Governos estaduais } \\
\text { conquistados (\%) }\end{array}$} & Frequência acumulada (\%) \\
\hline MDB & $30,3(79)$ & 30,3 \\
\hline PSDB & $16,5(43)$ & 46,8 \\
\hline PT & $10,3(27)$ & 57,1 \\
\hline DEM & $10,3(27)$ & 67,4 \\
\hline PSB & $8,8(23)$ & 76,2 \\
\hline PP & $8,4(22)$ & 84,6 \\
\hline PDT & $5,0(13)$ & 89,6 \\
\hline Outros & $10,4(28)$ & 100 \\
\hline Total & $100(261)$ & 100 \\
\hline
\end{tabular}

Fonte: TSE, elaboração própria. Entre parênteses, o número de casos $(\mathrm{N})$.

Como se pode observar, há grande presença de governadores vinculados ao campo ideológico do centro, com MDB e PSDB perfazendo quase a metade de governadores eleitos no período abrangido. Se desconsiderássemos o período de 19821986, o MDB continuaria preponderante, mas com apenas 48 governadores eleitos. 
Ao longo da análise, também salientaremos mudanças nos objetivos dos partidos longitudinalmente, permitindo mapear mudanças de aspectos organizacionais.

Quanto aos partidos de esquerda, o PT e PSB possuem preponderância em relaçáo ao PDT atualmente. Contudo, este movimento na esquerda se dá a partir de 1994, quando o número de governos comandados pelo PT e PSB começa a se distanciar do PDT. Já em relação aos partidos de direita, percebe-se uma concentração de ganhos eleitorais em certos períodos. No caso do PP, quando este se chamava PDS, em 1982, houve doze governadores eleitos pelo partido, ou seja, mais de $50 \%$ dos governadores de todo o período. Já quanto ao DEM, antigo PFL, nas eleições da década de noventa, foi onde houve mais de $60 \%$ da eleição de seus governadores. Assim sendo, mostraremos como o indicador IOP também faz sentido se pensarmos os partidos políticos em termos históricos, mostrando metas e desafios distintos ao longo do tempo.

Para iniciarmos a aplicação do Índice de Objetivos Partidários, começamos pela sua primeira dimensão, que é a de perseguidor de votos (vote-seeking). Conforme descrita anteriormente, tal dimensão é medida pela eficiência absoluta nas eleiçôes; em outras palavras, qual a porcentagem de vitórias nas disputas do partido (GIORA e GRABOSKI, 2015).

Gráfico 1 - Índice de eficiência absoluta (Ief) entre 1982-2018 nos governos estaduais

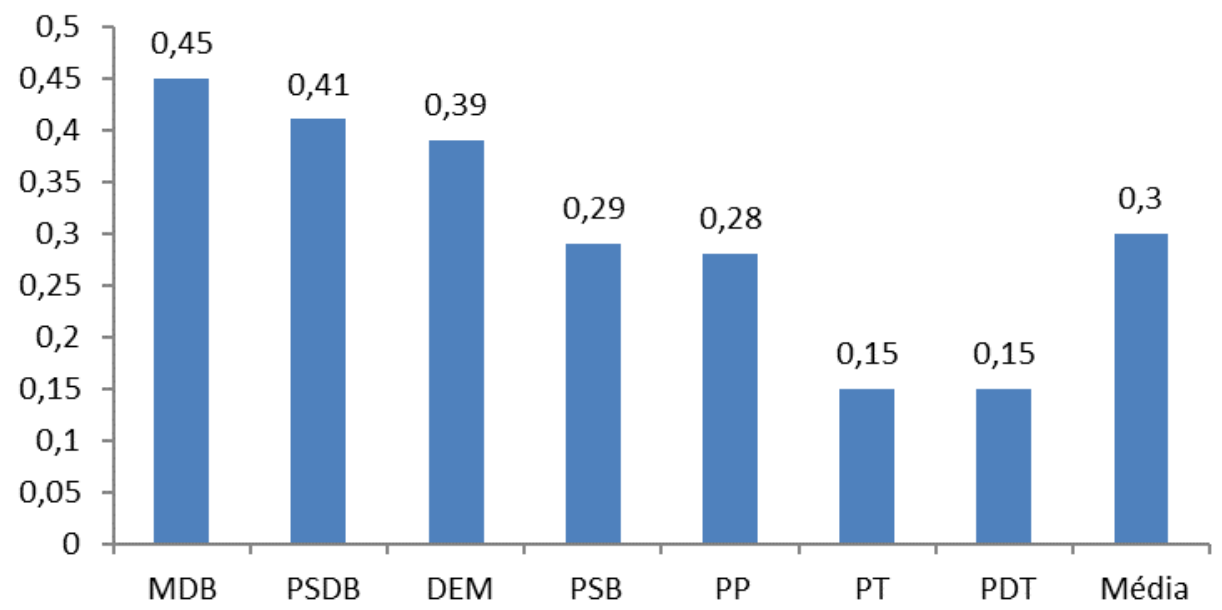

Fonte: TSE, elaboração própria. 
Poder-se-ia pensar que existe um cálculo racional das lideranças partidárias em concorrer somente quando houver um maior potencial de chances de vitória. Nesse sentido, correlacionamos o número de governos estaduais (Tabela 1) com a eficiência absoluta (Gráfico 1). O resultado é: 0,73 (Pearson). Existe, portanto, uma alta correlação entre as variáveis. De certa maneira, existe uma tendência de os partidos mais competitivos serem voltados mais ao vote-seeking. Como demonstraremos mais adiante, existe uma tendência das elites partidárias em maximizar outras dimensóes quando a vitória política náo pode ser alcançada por meio da conquista do governo estadual. Assim, os políticos realizam cálculos eleitorais para maximizar as potencialidades da organização. Contudo, como pode ser observado, o PT é o único partido que destoa bastante quando realizamos a correlação. Se desconsiderássemos a organização, o coeficiente de correlação subiria para 0,8 (Pearson). A explicação é temporal e reforça a utilização do IOP; expliquemos.

O PT, até a eleição de 1994, tinha eleito somente dois governadores, apesar de ter concorrido em oitenta e três eleiçóes, obtendo um Ief de apenas 0,02. Tal fraqueza de objetivo de vote-seeking coaduna com toda uma literatura sobre a organizaçáo partidária nesse período que demonstra que o PT possuía características mais próximas de um partido de massas do que de um partido catch-all (MENEGUELLO, 1989; KINZO, 1993; MAINWARING, 2001; KRAUSE e GODOI, 2010; AMARAL, 2011). Todavia, quando analisamos as eleiçóes de 1998 em diante, o Ief passa para 0,25 , mostrando um alto salto no tocante à eficiência absoluta. Assim, é interessante observar que, desde meados da década de noventa, o PT tratou de maximizar mais sua participação para governos estaduais. Assim, o partido deixou de participar de algumas disputas quando não era favorito, ainda que, comparativamente a outras organizaçóes, o partido ainda concorra em contextos eleitorais não favoráveis. Desta maneira, o caso específico do PT reforça a compreensão de bom uso do nosso indicador, já que houve claras mudanças organizacionais ao longo do tempo (VEIGA, 2007; SAMUELS, 2008; RIBEIRO, 2009; KRAUSE, REBELLO e SILVA, 2015).

Os três partidos mais eficientes, MDB, PSDB e DEM são aqueles mais próximos das características vote-seeking. Neste diapasão, é importante salientar que a literatura enfatizava que estes partidos seriam mais próximos do que se chama catch-all parties. Não é objetivo aqui resgatar a discussão dessa tipologia, mas, em geral, essas organizaçóes são mais permeáveis ideologicamente. O PSDB, por exemplo, em seu início, foi pensado para ter um conteúdo programático vinculado à social-democracia, marcando uma posição mais à esquerda que o então MDB. Todavia, já no governo 
FHC, alguns posicionamentos mais próximos do neoliberalismo, a oposição ao governo do PT e a incorporaçáo de políticos visivelmente mais liberais fizeram com que a classificação ideológica do PSDB se tornasse mais duvidosa, podendo o partido ser enquadrado no campo da direita (MAYER, 2017). O MDB sempre foi um conjunto de frentes e disputas estaduais já durante a ditadura militar (KINZO, 1993). Um dos reflexos disso foi sua alta indisciplina partidária na Câmara dos Deputados (MAINWARING, 2001). Já o DEM sempre foi associado mais ao campo ideológico da direita, embora com alteraçóes ao longo do tempo (REBELLO, 2012).

Em termos eleitorais, tais partidos nunca conseguiram uma grande cristalização da preferência do eleitorado (VEIGA, 2011). Também são partidos que sempre dependeram do financiamento eleitoral de organizaçóes privadas, não possuindo um financiamento por meio da militância, por exemplo. Destarte, há indicativos de que tais organizaçôes, no caso dos governos estaduais, são perseguidoras de votos, ainda que outras dimensões sejam também relevantes, como veremos na sequência.

As outras organizaçóes, PSB, PP e, principalmente o PDT, afastam-se de objetivos de vote-seeking. Em muitas eleiçóes, essas legendas concorreram, mas sem sucesso, mostrando que o objetivo maior não era o de ganhar eleiçóes. No caso específico do PDT, até a eleição de 2006, desde 1982, em média, a legenda lançava dez candidatos a governador. Contudo, desde 2010, esta média cai para quatro. Seria interessante um estudo mais específico do porquê dessa mudança.

Nossa segunda dimensão do IOP é a busca por políticas públicas (policyseeking). Para essa medição utilizamos, como discutido anteriormente, o Índice de consistência ideológica (Ici). Esse índice se baseia em análises prévias na literatura (KRAUSE e GODOI, 2010). Em geral, acredita-se que partidos muito ideológicos não se situam em coligaçóes de campos ideológicos opostos. A seguir, vemos como a maioria dos partidos políticos está longe de ser um grande perseguidor de políticas públicas. 


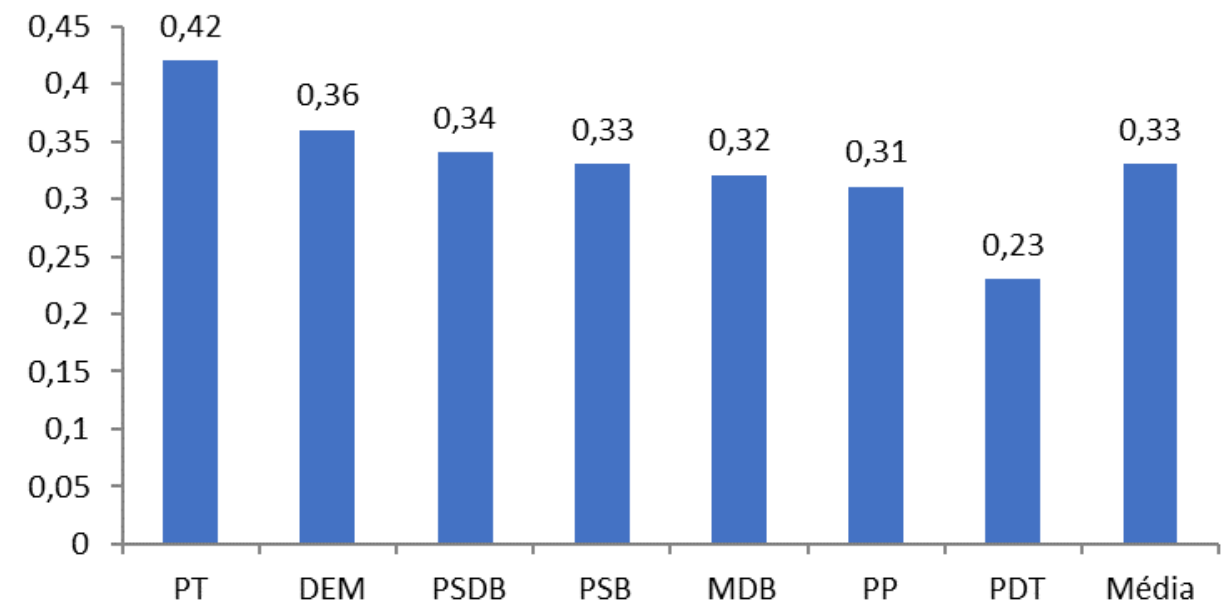

Fonte: TSE, elaboração própria.

Podemos dividir a aproximação das organizaçóes em dois grupos: todos os partidos, incluindo o PT de 2002 em diante; e o PT de 1982 a 1998. Caso considerássemos somente o PT antigo, seu Ici seria de 0,81, mostrando um partido bastante preocupado em maximizar policy. Em contrapartida, de 2002 até 2018 seu índice seria de apenas 0,18 , mostrando uma organização totalmente diversa. Da mesma forma que no Gráfico 1, o resultado indicado no caso do PT vai ao encontro do que compreendemos como o valor heurístico de nosso indicador. Mais uma vez, a alteraçáo organizacional petista pode ser visualizada temporalmente, indicando um distanciamento de um partido de massas. A tese de distanciamento de uma organização de massas pode ser avaliada pelo grau de mudança petista no que tange aos seus programas de governo na disputa presidencial, com forte mudança de conteúdo (REISMAN, 2016).

No caso das outras organizações partidárias, em geral, não houve mudanças muito significativas, tendo a maior parte dos partidos um objetivo relativamente pequeno na aplicaçáo de policy. Todavia, como discutido anteriormente, esse objetivo não é totalmente desconsiderado quando falamos em elites partidárias, até mesmo porque ainda existe uma visível escala ideológica entre as legendas (MADEIRA e TAROUCO, 2015). 
Nossa última dimensão, o office-seeking, ou perseguidor de cargos, é, possivelmente, a impressão mais clara que a populaçáo brasileira tem sobre os partidos políticos. Em geral, nos surveys aplicados nos últimos anos no Brasil, a instituição partido político é tida como a menos confiável. Isso se deve bastante ao fato de que, no pensamento do brasileiro médio, as organizaçôes partidárias são muito voltadas a se favorecer e se beneficiar do poder. Algo que chamamos, na literatura, de rent-seeking, ou extrair rendas para si. Nesse sentido, o Gráfico 3 demonstra que talvez a "sabedoria popular" não esteja tão equivocada neste ponto.

Gráfico 3 - Índice de coligaçôes (Icol) entre 1982-2018 nos governos estaduais

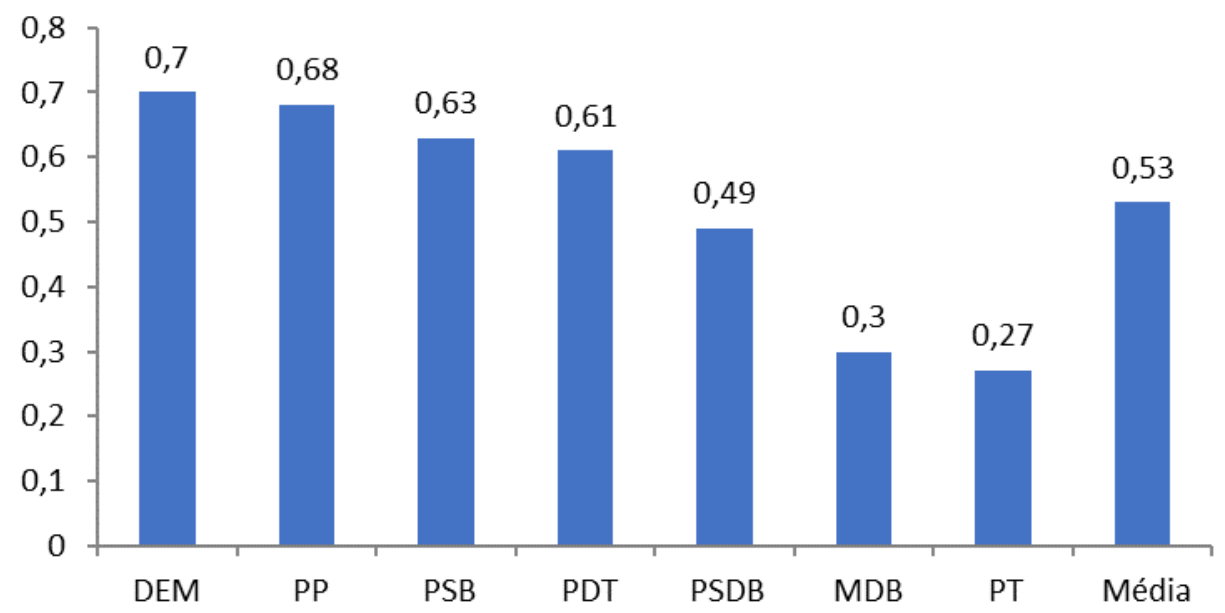

Fonte: TSE, elaboração própria.

Os resultados indicam uma forte inclinação partidária ao office-seeking para a maioria dos partidos. Em verdade, à exceção de MDB e PT, o restante das legendas maximizam mais cargos do que outros objetivos. Pode parecer contraintuitivo o fato do MDB, tido como partido altamente governista, ter uma procura menor por cargos. Todavia, não se deve esquecer que este índice é pensado sobre o comportamento organizacional em nível de candidaturas estaduais. Em tese, o MDB sempre foi o partido mais forte em termos de estrutura organizacional nos estados. Tanto o é que, junto do PT, ambas organizaçóes estiveram presentes em mais de 95\% das eleiçóes estaduais - indicador que mostra o grande grau de penetraçáo nacional destas 
organizaçóes. O PSDB é um partido político que apresenta um grau razoável de busca por cargos, mas menor do que PP, DEM e PSB e PDT. Junto do MDB, o PSDB é um partido com boa capacidade de vitória eleitoral nos estados. Deste modo, parece claro existir uma associação entre a força potencial de vitória com a busca por cargos. Os três maiores partidos em termos de governos estaduais conquistados (MDB, PSDB e PT) podem prescindir de conquistar cargos por meio de coligaçóes, tendo relativa vantagem competitiva sobre outras organizaçóes. No caso de PP, DEM, PDT e PSB, sua sobrevivência organizacional depende mais da conquista do Estado, por meio de cargos, sendo legendas com objetivos que maximizam o office-seeking.

O PT, novamente, mostra como nosso indicador pode ser relevante. Como dito anteriormente, até 1994, a organização apresenta resultados bem diferentes quanto à busca por cargos. Entre 1982 e 1994, seu Icol é de apenas 0,13. Já de 2002 em diante, esse índice sobe para 0,36. Portanto, o Partido dos Trabalhadores, que antes se negava a participar de coligaçóes e de governos estaduais quando não era cabeça de chapa, começou a mudar sua estratégia, ainda que esteja longe de ser um perseguidor desses objetivos se comparado com outras legendas.

A direita, que já foi tida como clientelista em alguns estudos (MAINWARING, MENEGUELLO e POWER, 2000), mostra como a sua participação no Estado é essencial para sua sobrevivência organizacional. Algo paradoxal, já que muitas dessas organizaçôes possuem conteúdo ideológico mais liberal. A busca por office-seeking já é pensada na formação da coligação, pensando em um futuro governo. $\mathrm{Na}$ dissertação de mestrado de Isadora Peron (2018), há vários indicativos de como os políticos buscam maximizar sua participação no governo, incluindo citaçôes explícitas de vários líderes partidários.

\section{Os partidos politicos em um triângulo tridimensional}

A bibliografia internacional sobre partidos políticos compreende diversos tipos partidários ao longo do tempo (GUNTHER e DIAMOND, 2003). Todavia, neste artigo, reduzimos nossa análise para três tipos ideais de partidos políticos, o que culmina com a escolha de estudar os três principais objetivos: vote, policy ou office (WOLINETZ, 2002).

Em geral, as organizaçóes partidárias brasileiras sob o prisma das disputas estaduais, se situam entre um campo razoável de busca por votos e políticas públicas e com certa proeminência na busca por cargos. Evidente que nossa proposta metodológica deve ser vista sob uma perspectiva crítica e deve ser testada em novos estudos, com nova base de dados. Ainda assim, seu uso parece ser promissor. 
Os partidos políticos tidos como o centro (MDB e PSDB) são aqueles mais vitoriosos e que apresentam o maior índice de eficiência absoluta. Assim, dentre as legendas brasileiras, tais organizaçôes são os maiores maximizadores de votos. Quando suas máquinas partidárias não objetivam vencer eleiçôes, procuram se manter no Estado por meio de coligaçóes, principalmente o PSDB. Tais organizaçóes também têm preocupação razoável quanto ao oferecimento de políticas públicas, estando muito próximas da maioria dos partidos políticos brasileiros.

No caso de partidos políticos à direita do espectro político (DEM e PP), tais partidos não têm sido muito competitivos no âmbito estadual. $\mathrm{O}$ índice de eficiência absoluta é razoável, e, no caso específico do DEM, pode-se afirmar uma organização mais preocupada em adquirir votos do que o PP. Em termos de busca por políticas públicas, o DEM também possui um índice um pouco superior ao $\mathrm{PP}$, e possivelmente isto se deva, em parte, a uma oposição sistemática dos Democratas quando o PT comandava a Presidência da República. O que mais chama atenção, no entanto, é sua alta procura por cargos, mostrando como a patronagem e o clientelismo continuam sendo importantes para tal campo ideológico (MAINWARING, MENEGUELLO e POWER, 2000).

Já quanto aos partidos de esquerda, podemos dividi-los em dois blocos: PT pré1998, e o PT atual juntamente com PDT e PSB. Atualmente, as legendas de esquerda têm uma preocupação menor quanto à busca por votos ou políticas públicas, afastandose das características de partidos políticos catch-all e, principalmente, de massas. Todavia, quanto à busca por cargos, à exceção parcial do PT, a esquerda também atua no mesmo sentido que a direita. São organizaçôes cuja sobrevivência depende de uma permanência no Estado, gerando uma forma de cartelização (KATZ e MAIR, 1997).

O PT, até a eleição de 1998, era um partido que não tinha o menor objetivo de cargos ou votos. Sua busca por policy era muito mais forte do que os outros objetivos. Assim, a literatura estava correta ao associar o Partido dos Trabalhadores à descrição duvergeriana de partido de massas (KINZO, 1993). Suas alteraçôes em nossos índices sugerem concordância com que o queríamos demonstrar. A seguir, os partidos políticos estão dispostos em um triângulo tridimensional, mostrando quais são seus principais objetivos. 
94 | Maurício Michel Rebello, Gustavo Giora e Matheus Henrique Gomes Pereira

Figura 2 - Representação ilustrativa do Índice de Objetivo Partidário (IOP) para as eleiçôes de 19822018

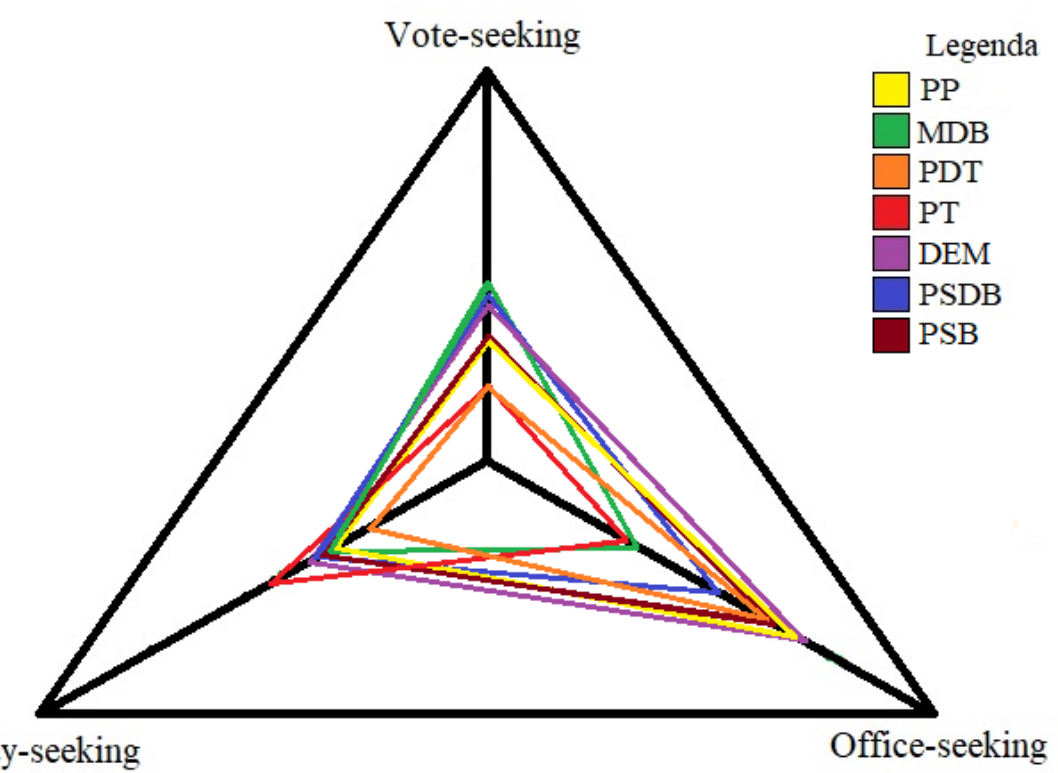

Policy-seeking

Fonte: TSE, elaboração própria.

\section{Considerações finais}

A construção de indicadores na Ciência Política tem dado respostas positivas à área, permitindo mensurar diversos fenômenos entre partidos e eleições, por exemplo. Nosso artigo tenta criar outro índice, o Índice de Objetivos Partidários (IOP).

Wolinetz (2002), ao descrever diferentes tipos de partidos, demonstra como as organizaçóes partidárias possuem objetivos distintos ao longo do tempo. Assim, os três tipos ideais de partidos políticos seriam o vote-seeking, policy-seeking e office-seeking. Da mesma forma que o autor, interpretamos que tais objetivos seriam os principais das organizaçóes partidárias ao longo do tempo. Assim, tentamos criar um indicador capaz de mensurar tais objetivos.

Destarte, por meio de dados eleitorais, realizamos um esforço para adaptar a interpretaçáo teórica à realidade do sistema eleitoral brasileiro. Assim, realizamos uma investigação de todas as eleiçôes para governos estaduais, desde 1982 até 2018, entre os sete maiores partidos. Todos os dados foram extraídos do Tribunal Superior Eleitoral (TSE). 
De maneira geral, os dados encontrados vão de encontro à literatura brasileira sobre partidos políticos. Alguns partidos políticos objetivam uma maior conquista de votos, como é o caso mais específico de MDB e PSDB. A exceção do PT até 1998, as organizaçóes partidárias brasileiras possuem certo distanciamento na busca por políticas públicas, principalmente o PDT. À exceçáo de MDB e PT, as outras legendas têm como maior objetivo o office-seeking, reforçando a ideia de que nossos partidos estão bem próximos do Estado e mais distantes da sociedade civil (KATZ e MAIR, 1997; MAIR, 2003).

Esperamos que o IOP seja alvo de escrutínio por parte da Ciência Política. Assim, teremos um material metodológico de fácil reprodutibilidade para investigar os partidos políticos. Afinal, as organizaçóes partidárias ainda são elementos cruciais para compreendermos as democracias contemporâneas.

Maurício Michel Rebello é Doutor em Ciência Política, pela Universidade Federal do Rio Grande do Sul (UFRGS). Professor da Universidade Federal da Fronteira Sul (UFFS). E-mail: mmrebello@yahoo.com.br.

Gustavo Giora é Doutor em Ciência Política, pela UFRGS. Professor da UFFS. E-mail: gustavo.giora@uffs.edu.br.

Matheus Henrique Gomes Pereira é Licenciado em Ciências Sociais, pela UFFS. E-mail: mgp_96@live.com.

\section{Referências}

ADSERÁ, Alicia; BOIX, Carles; PAYNE, Mark. Are you being served? Political accountability and quality of government. Journal of Law, Economics and Organization, v. 19, n. 2, p. 445-490, 2003.

AMARAL, Oswaldo. Ainda conectado: o PT e seus vínculos com a sociedade. Opinião Pública, v. 17, n. 1, p. 1-44, 2011.

ARTHUR, Brian W. Increasing Returns and Path Dependence in the Economy. Ann Arbor: University of Michigan Press, 1994.

BARTOLINI, Stefano; MAIR, Peter. Identity, competition, and electoral availability: the stabilization of European electorates. Cambridge: Cambridge University Press, 1990. 
DOWNS, Anthony. An economic theory of democracy. New York: Harper and Row, 1999. Originalmente publicado em 1957.

DUVERGER, Maurice. Os Partidos Políticos. Rio de Janeiro: Zahar, 1970. Originalmente publicado em 1951.

GIORA, Gustavo; GRABOSKI, Vilmar. Efectividad i Racionalidad: las elecciones municipales en Brasil (2008-2012). Lima: ALACIP, 2015.

GUNTHER, Richard; DIAMOND, Larry. Species of Political Parties: a New Tipology. Party Politcs, v. 9, n. 2, p. 167-199, 2003.

HAYEK, Friedrich. The Constitution of Liberty. Chicago: The University of Chicago Press, 1960.

KATZ, Richard; MAIR, Peter. Party Organization, Party Democracy, and the Emergence of the Cartel Party. In: MAIR, Peter. Party System Change. Oxford: Clarendon Press, 1997. p. 93-119.

KINZO, Maria. Radiografia do quadro partidário brasileiro. São Paulo: Fundação Konrad-AdenauerStiftung, 1993.

KIRCHHEIMER, Otto. The Transformation of the Western European Party Systems. In: LAPALOMBARA, Joseph; WEINER, Myron. Political Parties and Political Development. New Jersey: Princeton University Press, 1966. p. 50-60.

KRAUSE, Silvana; GODOI, Pedro. Coligaçóes eleitorais para os executivos estaduais (1986-2006): padrões e tendências. In: KRAUSE, Silvana; DANTAS, Humberto; MIGUEL, Luis Felipe (Orgs.). Coligaçóespartidárias na nova democracia brasileira: perfis e tendências. Rio de Janeiro: Fundação Konrad Adenauer, 2010. p. 41-98.

KRAUSE, Silvana; REBELLO, Maurício; SILVA, Josimar. O perfil dos financiamentos dos partidos:o que as tipologias dizem? Revista Brasileira de Ciência Política, n. 16, p. 247-272, 2015.

LAAKSO, Markku; TAAGEPERA, Rein. "Effective" number of parties: a measure with application to Western Europe. Comparative Political Studies, v. 12, n. 1, p. 3-27, 1979.

LAPALOMBARA, Joseph. Reflection on political parties and political development, four decades later. Party Politics, v. 13, p. 141-154, 2007.

LIJPHART, Arend. Modelos de Democracia. Rio de Janeiro: Civilização Brasileira, 2003.

LIPSET, Seymour; ROKKAN, Stein. Cleavage structures, party systems, and voter alignments: an introduction. In: LIPSET, Seymour; ROKKAN, Stein. Party Systems and voter alignments: crossnational perspectives. New York: Free Press, 1967. p. 91-111.

MADEIRA, Rafael; TAROUCO, Gabriela. Os partidos brasileiros segundo seus estudiosos: análise de um expert survey. Civitas: Revista de Ciências Sociais, v. 15, n. 1, p. 24-39, 2015.

MAINWARING, Scott. Sistemas Partidários em novas democracias: o caso do Brasil. Porto Alegre: Mercado Aberto, 2001.

MAINWARING, Scott; MENEGUELLO, Rachel; POWER, Timothy. Partidos conservadores no Brasil Contemporâneo. São Paulo: Paz e Terra, 2000.

MAINWARING, Scott; TORCAL, Mariano. Teoria e institucionalização dos sistemas partidários após a terceira onda de democratização. Opinião Pública, v. 11, n. 2, p. 249-286, 2005.

MAIR, Peter. Os partidos políticos e a democracia. Análise Social, v. 28, n. 167, p. 277-293, 2003.

MANIN, Bernard. As metamorfoses do governo representativo. Revista Brasileira de Ciências Sociais, n. 29, p. 5-34, 1995.

MAYER, Rodrigo. Padróes de organizaçôes partidárias: 42 partidos políticos latino-americanos em perspectiva comparada. 2017. 296 f. Tese (Doutorado em Ciência Política) - Programa de Pós- 
Graduação em Ciência Política, Universidade Federal do Rio Grande do Sul (UFRGS), Porto Alegre, 2017.

MENEGUELLO, Rachel. Partidos e Governos no Brasil Contemporâneo (1985-1997). São Paulo: Paz e Terra, 1998.

MENEGUELLO, Rachel. PT: A Formação de Um Partido (1979-1982). São Paulo: Paz e Terra, 1989.

MICHELS, Robert. As tendências burocráticas das organizaçóes partidárias. In: CARDOSO, Fernando; ESTEVAM MARTINS, Carlos. Política \& Sociedade. São Paulo: Companhia Editora Nacional, 1979. v. 2. Originalmente publicado em 1912.

NORRIS, Pippa. Driving Democracy. New York: Cambridge University Press, 2008.

PANEBIANCO, Angelo. Modelos de partido: organização e poder nos partidos políticos. São Paulo: Martins Fontes, 2005.

PARANHOS, Ranulfo et al. Construindo indicadores sociais: uma revisão da bibliografia especializada. Perspectivas, v. 44, p. 147-173, 2013.

PEDERSEN, Morgens. On measuring party system change: a methodological critique and suggestion. Comparative Political Studies, v. 4, n. 12, 1980.

PERON, Isadora. As origens eleitorais das coalizóes governamentais no presidencialismo brasileiro. 2018. 110 f. Dissertação (Mestrado em Ciência Política) - Programa de Pós-Graduação em Ciência Política, Universidade de Brasília, Brasília, 2018.

PIERSON, Paul. Increasing Returns, Path Dependence, and the Study of Politics. The American Political Science Review, v. 94, n. 2, p. 251-267, 2000.

RAE, Douglas. The political consequences of electoral laws. New Haven: Yale University Press, 1967.

REBELLO, Maurício. Clivagens Sociais e sistema partidário brasileiro: o caso do PT. In: GALLO, Carlos; SOUZA, Bruno; LEÃO MARTINS, Joyce. Ciência Política Hoje. Porto Alegre, Evanfraef, 2013. p. 203-220.

REBELLO, Maurício. Ideologias partidárias no governo Lula: a percepção do eleitor. Civitas: Revista de Ciências Sociais, v. 12, n. 2, p. 298-320, 2012.

REISMAN, Leonardo. Coalizóes, partidos e programas de governo: a submissão das bandeiras partidárias ao mercado eleitoral. 2016. 98 f. Dissertação (Mestrado em Ciência Política) - Programa de Pós-Graduação em Ciência Política, Universidade de Brasília (UNB), Brasília, 2016.

RIBEIRO, Pedro. Robert Michels e a oligarquia do Partido dos Trabalhadores. Teoria \& Pesquisa, v. 18, n. 2, p. 119-150, 2009.

SAMUELS, David. A Evolução do Petismo (2002-2008). Opinião Pública, v. 14, n. 2, p. 302-318, 2008.

SARTORI, Giovanni. Partidos e Sistemas partidários. Rio de Janeiro: Zahar, 1982.

TSEBELIS, George. Jogos Ocultos: Escolha Racional no Campo da Política Comparada. São Paulo: Universidade de São Paulo, 1998.

VAN BIEZEN, Ingrid; KOPECKÝ, Petr. The State and the Parties: Public Funding, Public Regulation and Rent-Seeking in Contemporary Democracies. Party Politics, v. 13, n. 2, p. 235-254, 2007.

VEIGA, Luciana. O partidarismo no Brasil (2002/2010). Opinião Pública, v. 17, n. 2, p. 400425, 2011. 
98 Maurício Michel Rebello, Gustavo Giora e Matheus Henrique Gomes Pereira

VEIGA, Luciana. Os partidos políticos na perspectiva dos eleitores: mudanças e continuidades na identificação partidária e na avaliação das principais legendas após 2002. Opinião Pública, v. 13, n. 2, p. 340-365, 2007.

WOLINETZ, Steven. Beyond the Catch-All Party: Approaches to the Study of Parties and Party Organization in Contemporary Democracies. In: GUNTHER, Richard; MONTERO, José; LINZ, Juan. Political Parties. Old Concept and New Challenges.Oxford University Press, 2002. p. 136-165.

ZUCCO, Cezar. Esquerda, Direita e Governo. In: POWER, Timothy; ZUCCO, Cezar. O Congresso por ele mesmo. Belo Horizonte: Editora UFMG, 2011. p. 37 -60.

Texto recebido em $1^{\circ}$ de maio de 2020. Aprovado em 15 de setembro de 2020. 